Electronic Supporting Information

\title{
Theoretical Study of Low-lying Triplet States of Aniline
}

Xin-Juan Hou, Phung Quan, Tibor Höltzl, Tamás Veszprémi, Minh Tho Nguyen

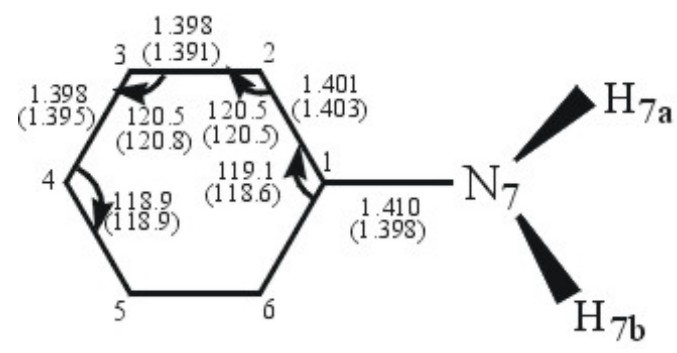

Figure 1S. CASSCF and B3LYP/6-311++G(d,p) (in parentheses) optimized geometric parameters for aniline at ground singlet state . 
a) Geometry, natural charges and

Wiberg indices

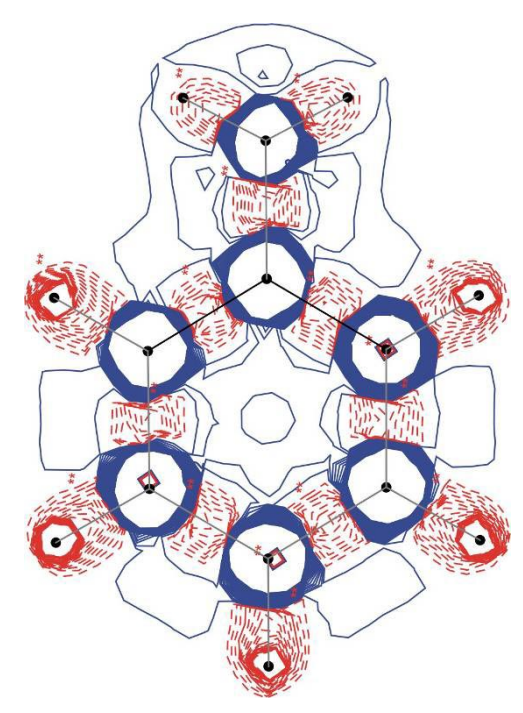

c) Laplacian

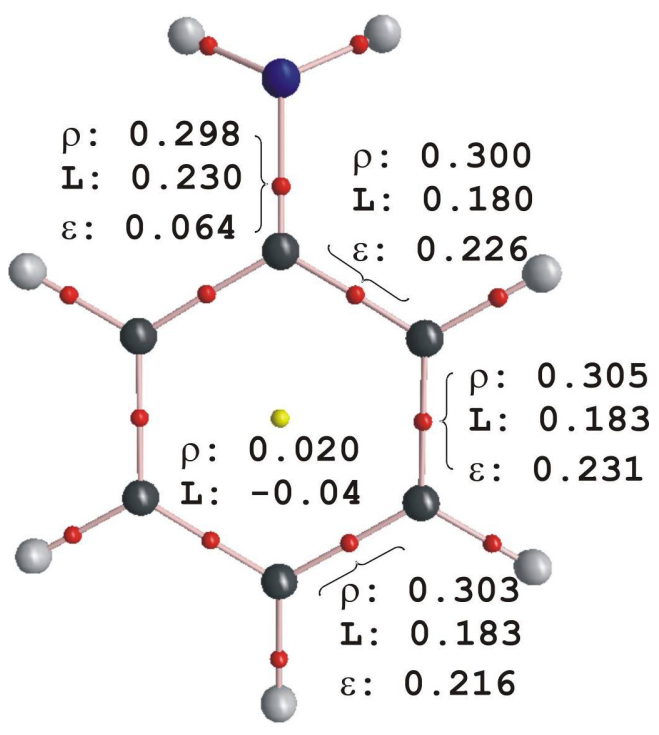

b) Topology of $\rho(\mathbf{r})$

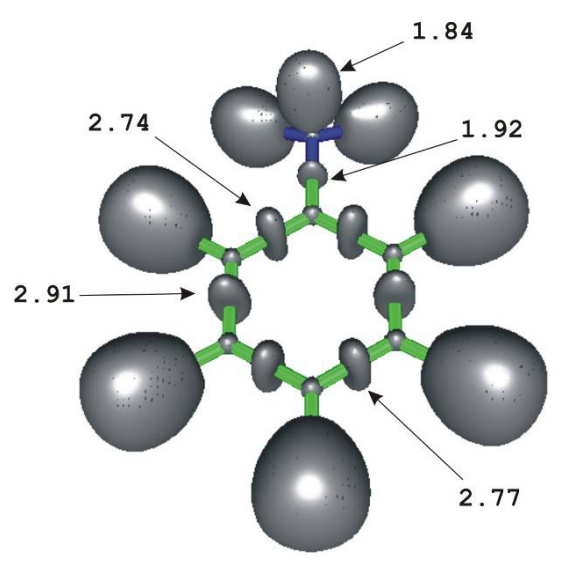

d) ELF

Figure 2S. Summary of electronic distribution in aniline. (a) bond distances ( $)$, NBO charges [bracket, in a.u.] and Wiberg indices (parentheses, in a.u.). (b) topololy of the electron density determined from atoms-in-molecules calculations: $\rho(\mathbf{r})=$ electron density (a.u), $\mathrm{L}=$ Laplacian of the density defined as $\mathrm{L}(\mathbf{r})=-\nabla^{2} \rho(\mathbf{r})$ (a.u.), and $\varepsilon=$ ellipticity of the bond critical point. (c) Laplacian map of the density, and (d) Isosurfaces of the electron localization function, $E L F=0.87 \mathrm{a}$.u.; the values are the populations of the valence basins (a.u.). 


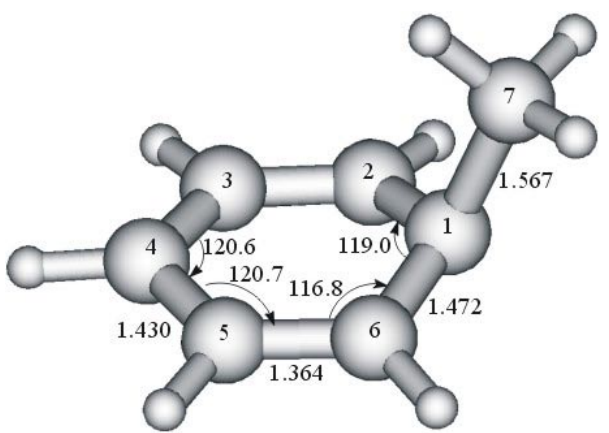

Dih $(1,2,3,4)-9.8$

Dih $(7,1,2,3)-106.4$

P1

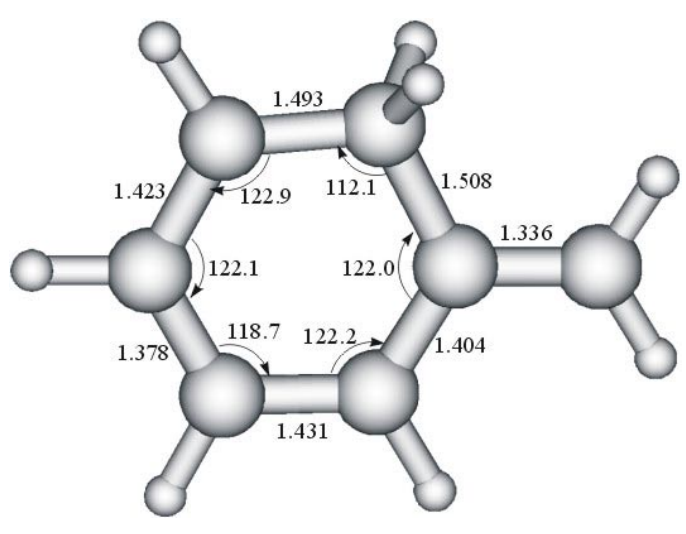

P3

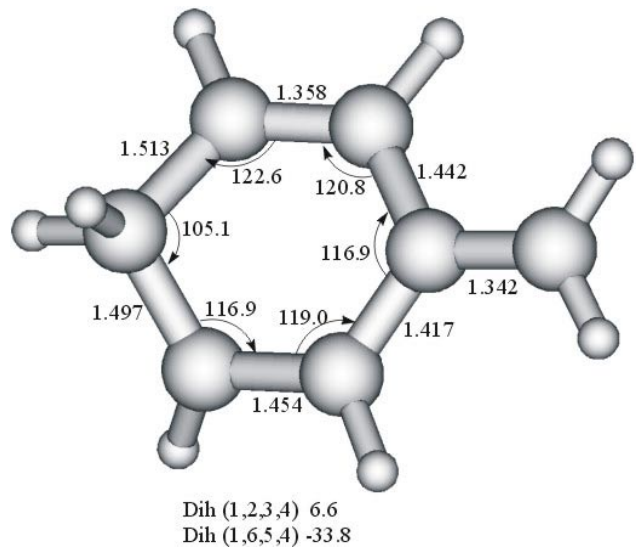

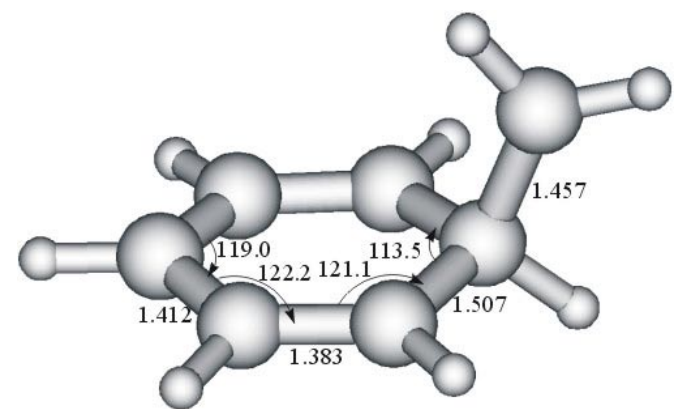

$\operatorname{Dih}(1,2,3,4)-1.7$

Dih $(7,1,2,3)-106.4$

P2

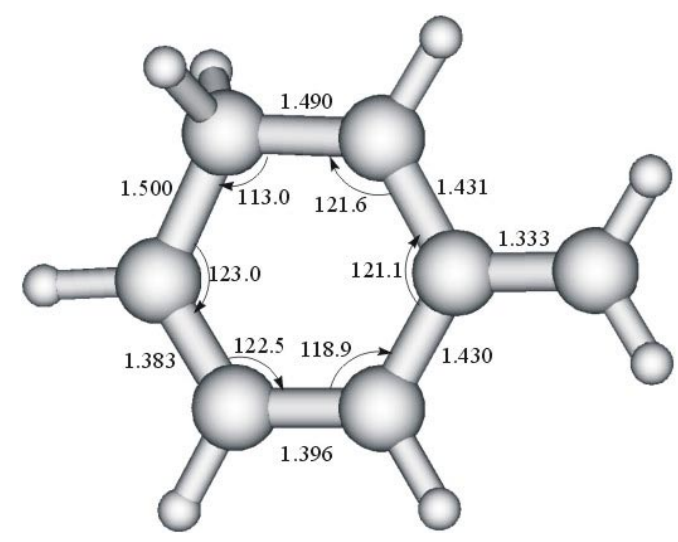

P4

\section{P5}

Figure 3S. Selected (U)B3LYP/6-311++G(d,p) geometrical parameters of protonated aniline in the lowest-lying triplet state. Bond distances are given in angstrom and bond angles in degree. 